TITLE:

\title{
Potential lethal and non-lethal effects of predators on dispersal of spider mites.
}

$\operatorname{AUTHOR}(\mathrm{S}):$

Otsuki, Hatsune; Yano, Shuichi

CITATION:

Otsuki, Hatsune ...[et al]. Potential lethal and non-lethal effects of predators on dispersal of spider mites.. Experimental \& applied acarology 2014, 64(3): 265-275

ISSUE DATE:

2014-05-28

URL:

http://hdl.handle.net/2433/200209

\section{RIGHT:}

The final publication is available at Springer via http://dx.doi.org/10.1007/s10493-0149824-9.; This is not the published version. Please cite only the published version.; この論 文は出版社版でありません。引用の際には出版社版をご確認ご利用ください。 


\section{Title}

2 Potential lethal and non-lethal effects of predators on dispersal of spider mites

3

\section{Authors}

$5 \quad$ Hatsune Otsuki ${ }^{a^{*}}$, Shuichi Yano ${ }^{a}$

6 a Laboratory of Ecological Information, Graduate School of Agriculture, Kyoto University,

7 Sakyo-ku, Kyoto 606-8502, Japan

8 * Corresponding author:

$9 \quad$ E-mail: ootsuki.hatsune.44e@st.kyoto-u.ac.jp

10 Telephone and fax: +81-75-753-6144 
11 Abstract Predators can affect prey dispersal lethally by direct consumption or non-lethally by making prey hesitate to disperse. These lethal and non-lethal effects are detectable only in systems where prey can disperse between multiple patches. However, most studies have drawn their conclusions concerning the ability of predatory mites to suppress spider mites from observations of their interactions on a single patch or on heavily infested host plants where spider mites could hardly disperse toward intact patches. In these systems, specialist predatory mites that penetrate protective webs produced by spider mites quickly suppress the spider mites, whereas generalist predators that cannot penetrate the webs were ineffective. By using a connected patch system, we revealed that a generalist ant, Pristomyrmex punctatus Mayr (Hymenoptera: Formicidae), effectively prevented dispersal of spider mites, Tetranychus kanzawai Kishida (Acari: Tetranychidae), by directly consuming dispersing individuals. We also revealed that a generalist predatory mite, Euseius sojaensis Ehara (Acari: Phytoseiidae), prevented between-patch dispersal of T. kanzawai by making them hesitate to disperse. In contrast, a specialist predatory mite, Neoseiulus womersleyi Schicha, allowed spider mites to escape an initial patch, increasing the number of colonized patches within the system. Our results suggest that ants and generalist predatory mites can effectively suppress Tetranychus species under some conditions, and should receive more attention as agents for conservation biological control in agroecosystems.

28 Keywords Dispersal • Anti-predator behavior • Conservation biological control • 


\section{Introduction}

Although successful dispersal is crucial for prey organisms that utilize patchy resources, predators

prevent prey dispersal by consuming dispersing individuals (Young and Lockley 1988; Bonnet et al.

1999; Hiddink et al. 2002) or making them hesitate to disperse. Prey individuals that stay in a refuge

suffer reduced feeding time (Koivula et al. 1995; Dill and Fraser 1997), reduced mating opportunities

(Sih 1994; Cooper 1999), and physiological costs from unfavorable conditions in refuges (Wolf and

Kramer 1987; Martin and Lopez 1999). Such non-lethal effects (trait-mediated effects) of predators

can sometimes be comparable to those of direct consumption (density-mediated effects) (Lima 1998;

Werner and Peacor 2003; Nelson et al. 2004; Preisser et al. 2005; Creel and Christianson 2008).

Helle and Sabelis 1985; Johnson and Lyon 1988) that live in three-dimensional protective webs on

walking to a new resource (Brandenburg and Kennedy 1982; Kennedy and Smitley 1985; Margolies and Kennedy 1985), although they disperse aerially under some conditions (Margolies and Kennedy

1985; Smitley and Kennedy 1985). Because a single foundress can establish a new colony, dispersal

of mites can critically affect population structure in agroecosystems. Predatory mites are promising

biological control agents against spider mites in both conservation and augmentative biological con- 
spider mites is crucially important.

Nevertheless, most previous conclusions concerning the ability of predatory mites to suppress spider mites seem to have been drawn from observations of their interactions on a single patch or on heavily infested host plants, i.e. systems where spider mites could hardly disperse toward intact patches. In these systems, specialist predatory mites that can penetrate spider mite webs (Sabelis and Bakker 1992) can easily suppress the spider mites (e.g. Chant 1961; Hamamura 1986), leading such studies to suggest that specialist predatory mites are effective biological control agents. In contrast, generalist predatory mites that are hindered by the protective webs of spider mites (Osakabe 1988; McMurtry and Croft 1997; Ozawa and Yano 2009) seem ineffective for suppressing spider mites, and thus their effects on spider mite dispersal remains unexplored. We question these well-accepted concepts for two reasons. First, generalist predatory mites readily prey on spider mites outside their webs (Yano 2012; Otsuki and Yano 2014) and therefore may interrupt spider mite dispersal by consuming dispersing mites or by making spider mites hesitate to disperse. Second, because specialist predatory mites induce dispersal of spider mites (Bernstein 1984; Grostal and Dicke 1999; Oku et al. 2004; Bowler et al. 2013), specialist predators may increase the spread of spider mite colonies. These putative density- and trait-mediated effects of predators on spider mites are detectable only in systems where dispersal of mites toward intact patches is allowed.

We used four species in this study: the spider mite Tetranychus kanzawai Kishida (Acari:

Tetranychidae), the specialist predatory mite Neoseiulus womersleyi Schicha (Acari: Phytoseiidae), 
68 the generalist predatory mite Euseius sojaensis Ehara, and the generalist ant Pristomyrmex punctatus

69 Mayr (Hymenoptera: Formicidae). Neoseiulus womersleyi and E. sojaensis are native predators of $T$.

70 kanzawai in Japan (Hamamura 1986; Osakabe et al. 1986; Amano 1996). Pristomyrmex punctatus is

71 a potential predator of T. kanzawai (Otsuki and Yano 2014) which often co-occurs with T. kanzawai

72 on wild plants such as Cayratia japonica (Thunb.) Gagnep (Vitaceae) (Yano, personal observation).

73 All of these species are ambulatory dispersers, so we can easily observe their interactions in micro-

74 cosms of connected patches. Using this system, we examined the following two hypotheses: (i) gen-

75 eralist ants and predatory mites that cannot penetrate spider mite webs can nonetheless prevent dis-

persal of T. kanzawai, and (ii) specialist predatory mites that penetrate spider mite webs may promote

dispersal and patch colonization by T. kanzawai in the system.

79 Materials and methods

81 Animals

83 We collected individuals of T. kanzawai from convolvulus Calystegia japonica Choisy (Convolvu-

84 laceae) in Kyoto, Japan. The population was then maintained on expanded primary leaves of kidney

85 bean, Phaseolus vulgaris L. (Fabaceae), which were pressed onto water-saturated cotton in Petri

86 dishes (90 mm in diameter, $14 \mathrm{~mm}$ in depth; hereafter "leaf discs") to prevent mites from escaping. 
87 We collected $N$. womersleyi from Rosa centifolia L. (Rosaceae) in Nara, Japan. The population was reared on leaf discs that were infested with T. urticae as prey (30-50 female adults and individuals of other stages per leaf). We collected E. sojaensis from kudzu vines, Pueraria lobata (Willd) Ohwi, in Kyoto and reared them on tea pollen on leaf discs. The leaf discs were placed in transparent plastic containers.

We collected 10,000 to 20,000 P. punctatus ants from a decayed tree on Mt. Yoshida in Kyoto and divided them into colonies of ca. 500 ants each. Since $P$. punctatus does not have a queen, and the workers can reproduce thelytokously (Mizutani 1980; Itow et al. 1984), we can consider ant individuals collected from one colony as an inbred strain that has minimal genetic variation, and we can easily replicate ant colonies with a fixed number of workers in individual microcosms. Each colony was reared in a microcosm constructed from a transparent plastic container $(220 \times 300 \times 60$ mm; Fig. 1). We coated the interior walls of the container with talc powder to prevent ants from escaping. A Petri dish (85 $\mathrm{mm}$ in diameter, $11 \mathrm{~mm}$ in depth) with a 6-mm plaster layer on the bottom was used as an artificial ant nest. The dish cover was painted with red pigment to encourage settlement. We added water on the plaster twice a week to maintain moisture. The ants were fed water and reproduction.

All mites and ants were reared at a constant temperature of $25^{\circ} \mathrm{C}$, with $50 \%$ relative humidity, and a L16:D8 photoperiod. All experiments were conducted under these conditions. 
Do ants prevent dispersal of spider mites?

109 To examine whether the generalist ant $P$. punctatus prevents dispersal of spider mites, we replicated

110 ant microcosms using two-patch setups (Fig. 1). We introduced 10 mated, 2-day-old female members

111 of T. kanzawai (hereafter "T. kanzawai females") onto each of 33 bean leaf squares $(20 \times 20 \mathrm{~mm}$;

112 initial patches), and allowed them to build webs. Since preliminary tests showed that T. kanzawai

113 females in the absence of ants start dispersing from the setup $24 \mathrm{~h}$ after the introduction, and that

114 webs build by 10 females for $24 \mathrm{~h}$ are effective against ant predation (also see Otsuki and Yano 2014),

115 we connected each leaf to another leaf square $(30 \times 30 \mathrm{~mm}$; second patches $)$ with a Parafilm bridge

116 (20 × $30 \mathrm{~mm}$; Fig. 1) after $24 \mathrm{~h}$ of the introduction. By connecting patches with a non-food flat sub-

117 strate on which spider mites cannot construct protective webs, we simulated mite dispersal from an

118 infested patch to an intact patch via a hostile environment without webs. The second patch was larger

119 than the initial one because a preliminary test showed that the larger patch size was necessary to re-

120 tain dispersed females on second patches during the experimental period. Each setup was placed on

121 wet cotton in a square dish $(87 \times 125 \times 8 \mathrm{~mm})$. Because of the surrounding water barrier, $T$.

122 kanzawai females could disperse only by walking across the bridges.

For the ant treatment $(\mathrm{n}=17)$, we placed each dish in the microcosm $50 \mathrm{~mm}$ away from an ar-

124 tificial ant nest (Fig. 1). For the non-ant treatments $(n=16)$, we placed each dish in the microcosm 
125 with an empty artificial ant nest, talc powder, and water to control for possible environmental biases.

126 Ants could easily access the spider mite leaves by walking across the wet cotton in the dish. About

$12710 \%$ of the ants were active and out of the nest in each colony (Otsuki, personal observation). To

128 eliminate the possible effect of learning, we used each colony only once.

After 3 days, when the differences between treatments were most conspicuous after the place-

ment in microcosms, we recorded the number of surviving T. kanzawai females on each patch and on

131 the bridge. We calculated the proportion of surviving females in the microcosm (survival rate), the

proportion of surviving females on the second patch (dispersal rate), and the proportion of surviving

females on the initial patch (remaining rate). We also recorded the state of dead females as either

drowning on the surrounding cotton or consumed by predators. Because $P$. punctatus always took the

prey mite away from the setup and because spider mites could not escape the setup (Otsuki and Yano

2014), we considered missing T. kanzawai females as having been consumed by P. punctatus. We

compared these rates between treatments using the generalized linear model with binomial error dis-

tribution (SAS Institute Inc. 2010) adjusted using Holm-Bonferroni correction.

Do generalist predatory mites prevent dispersal of spider mites?

To examine whether the generalist predatory mite E. sojaensis prevents dispersal of spider mites, we 
144 protect the female from E. sojaensis (Ozawa and Yano 2009; Yano 2012), and the leaf square used in

145 the above experiment $(20 \times 20 \mathrm{~mm})$ was too large to be exhausted by a $T$. kanzawai female, we in-

146 troduced one mated $T$. kanzawai female onto each of 153 smaller bean leaf squares $(10 \times 10 \mathrm{~mm}$;

147 initial patches). Since preliminary tests showed that T. kanzawai females in the absence of E. sojaen-

148 sis start dispersing from the setup on day 3, and that webs build for 3 days are effective against the

149 predators, we connected each leaf to another leaf square $(10 \times 10 \mathrm{~mm}$; second patches $)$ with a Para-

150 film bridge $(10 \times 30 \mathrm{~mm}$; Fig. 2$)$ after 3 days of the introduction. We then introduced one adult fe-

male E. sojaensis onto each of 80 setups (predator present), and 73 other setups served as controls

152 (predator absent). We did not introduce more than one predatory mite female on a setup because they

153 do not live in a group as a rule (Yano, unpublished). Because E. sojaensis females cannot penetrate

154 or walk on the complicated spider mite webs (Osakabe 1988), they prowled on the bridges and on the

155 second patches where spider mites could disperse.

After $24 \mathrm{~h}$, we recorded the state of T. kanzawai females and calculated survival, dispersal,

and remaining rates as described above. Six setups in which E. sojaensis had escaped were excluded

158 from the data. Therefore, the numbers of replications were 74 (predator present) and 73 (predator

159 absent). The above rates were compared between treatment groups using Fisher's exact test (SAS

Institute Inc. 2010) with Holm-Bonferroni correction

Do specialist predatory mites promote patch colonization by spider mites? 
164 To examine whether the specialist predatory mite $N$. womersleyi promotes dispersal of spider mites

165 and to demonstrate that the predator increases the number of prey patches, we introduced more than

166 one spider mite on a setup with more than two patches as shown in Fig. 3. We introduced five mated

167 T. kanzawai females onto each of 44 bean leaf squares $(10 \times 10 \mathrm{~mm}$; initial patches $)$ and allowed

168 them to oviposit for $24 \mathrm{~h}$, which was sufficient to retain $N$. womersleyi on the patch (see Results). We

169 then introduced one adult female $N$. womersleyi onto each initial patch in 20 setups (predator pre-

170 sent), and the other 24 setups served as controls (predator absent). We did not introduce more than

171 one predatory mite on a setup because of the same reason described above. After allowing the preda-

172 tors 30 min of acclimation, we connected each initial patch in all setups to four leaf squares $(10 \times 10$

173 mm; consecutive patches $)$ linearly with Parafilm bridges $(10 \times 30$ mm; Fig. 3).

After 2 days, when the differences between treatments were most conspicuous after predator

175 introduction, we recorded the number and state of $T$. kanzawai females on each patch and on the

176 bridge, and calculated survival and dispersal rates as described above. We also recorded the number

177 of newly colonized patches out of the four consecutive patches. We judged a patch with webs, injury

178 scars, eggs, and feces of T. kanzawai females as colonized regardless of the presence of females. Five

179 setups in which $N$. womersleyi had intruded into consecutive patches were excluded from the data.

180 Therefore, the numbers of replications were 15 (predator present) and 24 (predator absent), respec-

181 tively. The above rates were compared between treatment groups using the generalized linear model 
182 with binomial error distribution (SAS Institute Inc. 2010) adjusted using Holm-Bonferroni correc183 tion.

\section{Results}

Do ants prevent dispersal of spider mites?

In the presence of ants, significantly fewer T. kanzawai females survived and dispersed to the second

patch than in the absence of ants (Fig. 4a, b). All of the dead T. kanzawai females in the presence of ants were preyed upon. On the other hand, the number of T. kanzawai females that remained on the initial patch with the protective webs did not differ significantly between the treatments (Fig. 4c),

193 indicating that T. kanzawai females did not hesitate to move out of the refuges and disperse. There-

194 fore, it is likely that the ants lethally hindered the dispersal of T. kanzawai by consuming dispersing 195 females.

Do generalist predatory mites prevent dispersal of spider mites?

199 In both treatments, nearly all T. kanzawai females survived, and the survival rate did not differ sig200 nificantly between the treatments (Fig. 5a). All dead females in the presence of E. sojaensis were 
201 drowned, not preyed upon by E. sojaensis. In the presence of E. sojaensis, significantly fewer $T$.

202 kanzawai females dispersed to the second patch than in the absence of E. sojaensis (Fig. 5b).

203 The proportion of T. kanzawai females that remained on the initial patch did not differ significantly

204 between the treatments (Fig. 5c), suggesting that T. kanzawai females that had moved out of the ini-

205 tial patch could not access or colonize the second patch in the presence of E. sojaensis. Thus, E.

206 sojaensis non-lethally prevented the dispersal of T. kanzawai.

208 Do specialist predatory mites promote patch colonization by spider mites?

210 Neoseiulus womersleyi stayed under the webs on the initial patch. On the other hand, nearly all $T$.

211 kanzawai females survived under both treatments, and the survival rate did not differ significantly

212 between the treatments (Fig. 6a). None of the dead females was preyed upon by $N$. womersleyi. In

213 the presence of $N$. womersleyi, significantly more $T$. kanzawai females dispersed to other patches

214 (Fig. 6b), and females colonized significantly more patches in the presence than in the absence of $N$.

215 womersleyi (Fig. 6c). Therefore, $N$. womersleyi promoted the dispersal of T. kanzawai.

217 Discussion

219 By using a connected patch system that allowed prey dispersal toward an intact patch, we revealed 
220 that generalist predators that cannot suppress spider mites in systems with no opportunity for disper-

221 sal effectively prevented spider mite dispersal between patches either by directly consuming dispers222 ing prey (density-mediated effects) or by making them hesitate to colonize intact patches 223 (trait-mediated effects).

Although the generalist predatory mites did not directly reduce the survival of $T$. kanzawai

225 females, the predators would reduce the chance of feeding and oviposition of $T$. kanzawai females

226 that could not either access or colonize intact patches. This may be one of the mechanisms by which

227 generalist predatory mites, which cannot penetrate protective webs produced by spider mites (espe-

228 cially most Tetranychus species) do suppress mites in the field (McMurtry 1985; Duso 1988, 1989;

229 James 1990; but see Croft and MacRae 1992). Unlike specialist predatory mites, which depend on

230 spider mites, generalist predatory mites subsist on plant-derived alternative foods such as pollen

231 (McMurtry and Johnson 1965; Kennett et al. 1979) and pearl bodies (Ozawa and Yano 2009), and

232 also on mildew infecting plants (Duso et al. 2003), which are relatively stable food resources com-

233 pared with spider mites. Therefore, 'patrolling' of host plants of spider mites by generalist predatory

234 mites is less correlated with spider mite density (McMurtry 1992).

Tetranychus kanzawai females did not hesitate to disperse in the presence of ants and were

236 preyed upon, whereas females did hesitate to colonize intact patches in the presence of generalist

237 predatory mites. The difference may be attributed to the ants' higher ability to capture spider mites

238 due to their greater mobility and larger body size compared with predatory mites. Moreover, because 
239 ants can approach and attack T. kanzawai females from the surrounding wet cotton barrier, which

240 mites could not access, the females might not perceive approaching ants. In contrast, they may be

241 vigilant to chemical cues of predatory mites (Grostal and Dicke 1999; Škaloudova et al. 2007; Bow-

242 ler et al. 2013) that are confined on the leaves and bridges with the spider mites.

We also found that specialist predatory mites that suppress spider mites at high densities, let

244 spider mites escape and colonize new patches in systems where spider mites could disperse toward

245 intact patches. Previous studies also reported that specialist predatory mites promoted dispersal of the

246 spider mites (Bernstein 1984; Grostal and Dicke 1999; Oku et al. 2004; Bowler et al. 2013). Alt-

247 hough the experiment using setups with more than two patches apparently looks similar to the

248 two-patch system used by Bowler et al. (2013), the two experiments qualitatively differ in that

249 two-patch systems can only compare departure rates of mites from the initial patch, while systems

250 with more than two patches can compare the number of newly colonized patches in the presence or

251 otherwise of the predator. Thus, we further confirmed that the dispersal of spider mites in response to

252 the attack of specialist predatory mites increased the number of colonized patches. Because N. wom-

253 ersleyi females prefer spider mite eggs laid in the webs rather than adult females (Takafuji and Chant

254 1976; Fernando and Hassell 1980; Sabelis 1990; Blackwood et al. 2001; Furuichi et al. 2005), it is

255 not surprising that all T. kanzawai females escaped predation while predatory mites stayed on the ini-

256 tial patch. We predict that specialist predatory mites can rarely follow dispersed spider mites in the

257 wild, as there are many directions in which spider mites can escape. Although specialist predatory 
258 mites in the genera Phytoseiulus and Neoseiulus can follow trails left by a group of spider mites, they

259 cannot follow a trail left by a single spider mite female (Yano and Osakabe 2009; Shinmen et al. 260 2010).

Dispersed spider mite females can establish local populations, which are often in danger of

262 extinction because of larger predatory insects (Janssen et al. 1998), coincidental intraguild predation

263 by larger herbivores (Shirotsuka and Yano 2012), and natural or human-induced disturbance (e.g.

264 Das 1959). Although specialist predatory mites would impose short-term fitness costs on spider mites

265 by consuming eggs (e.g. Takafuji and Chant 1976), the predatory mites may reduce the extinction rate of spider mite metapopulations in the long term by increasing the number of local populations

267 (Levins 1969). On the other hand, generalist predators would impose long-term costs on spider mite metapopulations by inhibiting establishment of local populations and by imposing short-term costs on dispersing females as discussed above.

can be more effective agents for conservation biological control against Tetranychus species than can specialist predatory mites at least under some conditions. Particularly under low spider mite density, specialist predatory mites would scatter spider mite females, increasing the number of infested 274 patches in the area. Moreover, specialist predators in general do not remain on a reward-less patch 275 (Charnov 1976; Symondson et al. 2002) Thus, specialist predatory mites can suppress spider mite 276 populations only under high spider mite density (e.g. Burnett 1979; Janssen et al. 1997; Schausberger 
277 and Walzer 2001). From the viewpoint of conservation biological control strategy, using native gen-

278 eralist predatory mites that subsist on alternative food resources rather than specialist predatory mites

279 that depend on spider mites might maintain spider mites at low endemic densities. More importantly,

280 we suggest the significant lethal impacts of ants on spider mites that have not been considered in

281 discussions of conservation biological control against spider mites (but see Osborne et al. 1995). The

282 relative effects of generalist and specialist predators, as well as interactions between them, should be

283 examined in future studies in terms of sustainable management of spider mites.

\section{Acknowledgements}

We thank members of the Laboratory of Ecological Information for valuable suggestions and en-

couragement. This work was supported by the Japan Society for the Promotion of Science [Basis

289 Research C; Grant Number 21580066 to S. Y.].

\section{References}

293 Amano H (1996) Natural enemies. In: Ehara S, Shinkaji N (eds) Principles of plant acarology. Zen294 koku Noson Kyoiku Kyokai, Tokyo, pp 159-174 (in Japanese)

295 Bernstein C (1984) Prey and predator emigration responses in the acarine system Tetranychus urti- 
cae-Phytoseiulus persimilis. Oecologia 61:134-142. doi: 10.1007/BF00379099

Blackwood JS, Schausberger P, Croft BA (2001) Prey-stage preference in generalist and specialist phytoseiid mites (Acari: Phytoseiidae) when offered Tetranychus urticae (Acari: Tetranychidae) eggs and larvae. Environ Entomol 30:1103-1111. doi: 10.1603/0046-225X-30.6.1103

Bonnet X, Naulleau G, Shine R (1999) The dangers of leaving home: dispersal and mortality in snakes. Biol Conserv 89:39-50. doi: 10.1016/S0006-3207(98)00140-2

Bowler DE, Yano S, Amano H (2013) The non-consumptive effects of a predator on spider mites depend on predator density. J Zool 289:52-59. doi: 10.1111/j.1469-7998.2012.00961.x

Burnett T (1979) An acarine predator-prey population infesting roses. Res Popul Ecol 20:227-234

Chant DA (1961) An experiment in biological control of Tetranychus telarius (L.) (Acarina:

Tetranychidae) in a greenhouse using the predacious mite Phytoseiulus persimilis Athias-Henriot

Charnov EL (1976) Optimal foraging, the marginal value theorem. Theor Popul Biol 9:129-136

Cooper WE (1999) Tradeoffs between courting, fighting, and antipredatory behavior by a lizard,

Eumeces laticeps. Behav Ecol Sociobiol 47:54-59. doi: 10.1007/s002650050649

Creel S, Christianson D (2008) Relationships between direct predation and risk effects. Trends Ecol 
Evol 23:194-201. doi: 10.1016/j.tree.2007.12.004

Croft BA, MacRae IV (1992) Biological control of apple mites by mixed populations of Metaseiulus occidentalis (Nesbitt) and Typhlodromus pyri Scheuten (Acari: Phytoseiidae). Environ Entomol

$$
\text { 21:202-209 }
$$

Das GM (1959) Bionomics of the tea red spider, Oligonychus coffeae Nietner. Bull Entomol Res

$$
50: 265-274
$$

Dill LM, Fraser AHG (1997) The worm re-turns: hiding behavior of a tube-dwelling marine polychaete, Serpula vermicularis. Behav Ecol 8:186-193. doi: 10.1093/beheco/8.2.186

Duso C (1988) Minimum release of Kampimodromus aberrans (Oud.) to control tetranychid mites on grapevine. Preliminary reports. In: Cavalloro R (ed) Influence of Environmental Factors on the Control of Grape Pests, Diseases and Weeds. Proc Mtg EC Experts Grp, Thessaloniki, Greece

Duso C (1989) Role of the predatory mites Amblyseius aberrans (Oud.), Typhlodromus pyri Scheuten and Amblyseius andersoni (Chant) (Acari: Phytoseiidae) in vineyards. 1. The effects of single or mixed phytoseiid population releases on spider mite densities (Acari: Tetranychidae). J Appl Entomol 107:474-492. doi: 10.1111/j.1439-0418.1989.tb00283.x

Duso C, Pozzebon A, Capuzzo C, Bisol PM, Otto S (2003) Grape downy mildew spread and mite seasonal abundance in vineyards: evidence for the predatory mites Amblyseius andersoni and Typhlodromus pyri. Biol Cont 27:229-241. doi: 101016/S 1049-9644(03)00016-1

Fernando MHJP, Hassell MP (1980) Predator-prey responses in an acarine system. Res Popul Ecol 
335 Furuichi H, Oku K, Yano S, Takafuji A, Osakabe Mh (2005) Why does the predatory mite Neoseiulus 336 womersleyi Schicha (Acari: Phytoseiidae) prefer spider mite eggs to adults? Appl Entomol Zool 40:675-678. doi: 10.1303/aez.2005.675

338 Grostal P, Dicke M (1999) Direct and indirect cues of predation risk influence behavior and repro339 duction of prey: a case for acarine interactions. Behav Ecol 10:422-427. doi: 10.1093/beheco/10.4.422

341 Hamamura T (1986) Studies on the biological control of Kanzawa spider mite, Tetranychus tea fields (Acarina: Tetranychidae, Phytoseiidae). Bull Natl Res Inst Tea 21:121-201

Helle W, Sabelis MW (1985) Spider mites: their biology, natural enemies and control, vol 1A. Elsevier, Amsterdam

Hiddink JG, Kock RP, Wolff WJ (2002) Active pelagic migrations of the bivalve Macoma balthica

348 Itow T, Kobayashi K, Kubota M, Ogata K, Imai HT, Crozier RH (1984) The reproductive cycle of 349 the queenless ant Pristomyrmex pungens. Insectes Sociaux 31:87-102. doi: 10.1007/BF02223694 350 James DG (1990) Biological control of Tetranychus urticae (Koch) (Acari: Tetranychidae) in southern New South Wales peach orchards: the role of Amblyseius victoriensis (Acari: Phytoseiidae). 
353 Janssen A, van Gool E, Lingeman R, Jacas J, van de Klashorst G (1997) Metapopulation dynamics of 354 a persisting predator-prey system in the laboratory: time series analysis. Exp Appl Acarol 21:415-430. doi: 10.1023/A:1018479828913

Janssen A, Pallini A, Venzon M, Sabelis MW (1998) Behaviour and indirect interactions in food

Jeppson LR, Keifer HH and Baker TW (1975) Mites Injurious to Economic Plants. University of $360 \quad$ California Press, Berkeley, pp 370-376

Johnson WT, Lyon HH (1988) Insects That Feed on Trees and Shrubs, 2nd edn. Comstock Publishing Associates, Ithaca, pp 468-470

Kennedy GG, Smitley DR (1985) Dispersal. In: Helle W, Sabelis MW (eds) Spider mites: their biology, natural enemies and control. Elsevier, Amsterdam, pp 233-251 10.1007/BF02377513

Kennett CE, Flaherty DL, Hoffmann RW (1979) Effect of wind-borne pollens on the population dynamics ofAmblyseius hibisci (Acarina: Phytoseiidae). Entomophaga 24:83-98. doi: attack in dominant and subordinate willow tits. Ardea 83:397-404 biological control. Bull Entomol Soc Am 15:237-240 
372 Lima SL (1998) Nonlethal effects in the ecology of predator-prey interactions. Bioscience 48:25-34

373 Margolies DC, Kennedy GG (1985) Movement of the two spotted spider mite, Tetranychus urticae,

374 among hosts in a corn-peanut agroecosystem. Entomol Exp Appl 37:55-61. doi:

10.1111/j.1570-7458.1985.tb03452.x

Martin J, Lopez P (1999) When to come out from a refuge: risk-sensitive and state-dependent deci-

McMurtry JA (1982) The use of phytoseiids for biological control: Progress and future prospects. In:

Hoy MA (ed) Recent advances in knowledge of the Phytoseiidae. Publ. 3284. University of Cali-

enemies and control. Elsevier, Amsterdam, pp 327-332

McMurtry JA (1992) Dynamics and potential impact of 'generalist' phytoseiids in agroecosystems

10.1007/BF01200574

McMurtry JA, Johnson, HG (1965) Some factors influencing the abundance of the predaceous mite Amblyseius hibisci in southern California (Acarina: Phytoseiidae). Ann Entomol Soc Am 58:49-56 Ann Rev Entomol 42:291-321 
Kontyu 48:327-332.

392 Nelson EH, Matthews CE, Rosenheim JA (2004) Predators reduce prey population growth by induc393 ing changes in prey behavior. Ecology 85:1853-1858. doi: 10.1890/03-3109

394 Oku K, Yano S, Takafuji A (2004) Nonlethal indirect effects of a native predatory mite, Amblyseius womersleyi Schicha (Acari: Phytoseiidae), on the phytophagous mite Tetranychus kanzawai Ki-

Osakabe Mh (1988) Relationships between food substances and developmental success in Amblyseius sojaensis Ehara (Acarina: Phytoseiidae). Appl Entomol Zool 23:45-51

78:565-570

Otsuki H, Yano S (2014) Functionally different predators break down antipredator defenses of spider mites. Entomol Exp Appl 151:27-33. doi: 10.1111/eea.12164 tive food for a predatory mite Euseius sojaensis (Ehara) (Acari: Phytoseiidae). Ecol Res 24:257-262. doi: 10.1007/s11284-008-0501-5 
410 Preisser EL, Bolnick DL, Benard MF (2005) Scared to death? The effects of intimidation and con-

411 sumption in predator-prey interactions. Ecology 86:501-509. doi: 10.1890/04-0719

412 Sabelis MW (1990) How to analyse prey preference when prey density varies? A new method to dis-

413 criminate between effects of gut fullness and prey type composition. Oecologia 82:289-298. doi:

$414 \quad 10.1007 / \mathrm{BF} 00317473$

415 Sabelis MW, Bakker FM (1992) How predatory mites cope with the web of their tetranychid prey: a

416 functional view on dorsal chaetotaxy in the Phytoseiidae. Exp Appl Acarol 16:203-225. doi:

10.1007/BF01193804

Saito Y (1983) The concept of "life types” in Tetranychinae. An attempt to classify the spinning behaviour of Tetranychinae. Acarologia 24:377-391

SAS Institute Inc (2010) Using JMP 9 Cary, NC: SAS Institute Inc.

Schausberger P, Walzer A (2001) Combined versus single species release of predaceous mites: predator-predator interactions and pest suppression. Biol Control 20:269-278. doi:

10.1006/bcon.2000.0908

Shinmen T, Yano S, Osakabe Mh (2010) The predatory mite Neoseiulus womersleyi (Acari: Phytoseiidae) follows extracts of trails left by the two-spotted spider mite Tetranychus urticae (Acari: 
429 Sih A (1994) Predation risk and the evolutionary ecology of reproductive behavior. J Fish Biol

$430 \quad$ 45:111-130. doi: 10.1111/j.1095-8649.1994.tb01087.x

431 Škaloudova B, Zemek R, Krivan V (2007) The effect of predation risk in an acarine system. Anim

432 Behav 74:813-821. doi: 10.1016/j.anbehav.2007.02.005

433 Smitley DR, Kennedy GG (1985) Photo-oriented aerial-dispersal behavior of Tetranychus urticae

434 (Acari: Tetranychidae) enhances escape from the leaf surface. Ann Entomol Soc Am 78:609-614

435 Symondson WOC, Sunderland KD, Greenstone MH (2002) Can generalist predators be effective bi-

ocontrol agents? Annu Rev Entomol 47:561-594. doi: 10.1146/annurev.ento.47.091201.145240

Takafuji A, Chant DA (1976) Comparative studies of two species of predacious phytoseiid mites

Werner EE, Peacor SD (2003) A review of trait-mediated indirect interactions in ecological commu-

Wolf NG, Kramer DL (1987) Use of cover and the need to breathe: the effect of hypoxia on vulnera-

10.1007/BF00376988

Yano S (2012) Cooperative web sharing against predators promotes group living in spider mites. Bihav Ecol Sociobiol 66:845-853. doi: 10.1007/s00265-012-1332-5 
448 mites? Ecol Res 24:1173-1178. doi: 10.1007/s11284-009-0598-1

449 Young OP, Lockley TC (1988) Dragonfly predation upon Phidippus audax (Araneae, salticidae). J $450 \quad$ Arachnol 16:121-122

451 


\section{Figure captions}

454 Fig. 1 Experimental setup for testing whether the generalist ant Pristomyrmex punctatus prevent 455 dispersal of Tetranychus kanzawai. The two-patch setup was placed in a microcosm with and without 456 ants

Fig. 2 Experimental setup to compare the dispersal of Tetranychus kanzawai in the presence or ab-

sence of the generalist predatory mite Euseius sojaensis that cannot penetrate spider mite webs

Fig. 3 Experimental setup to compare the dispersal and new patch foundation of Tetranychus

kanzawai in the presence or absence of the specialist predatory mite Neoseiulus womersleyi that pen-

Fig. 4 Effects of the generalist ant Pristomyrmex punctatus on (a) survival, (b) dispersal and (c) re-

maining rates (mean $+\mathrm{SE}$ ) of the spider mite Tetranychus kanzawai. Asterisks indicate a significant

difference at $\mathrm{P}<0.01$ by the generalized linear model with binomial error distribution adjusted using

Holm-Bonferroni correction.

470 Fig. 5 Effects of the generalist predatory mite Euseius sojaensis on (a) survival, (b) dispersal and (c) 
471 remaining rate of the spider mite Tetranychus kanzawai. An asterisk indicates a significant differ472 entce at $\mathrm{P}<0.01$ by Fisher’s exact test with Holm-Bonferroni correction.

474 Fig. 6 Effects of the specialist predatory mite Neoseiulus womersleyi on (a) survival, (b) dispersal 475 and (c) patch colonization (mean + SE) of the spider mite Tetranychus kanzawai. Asterisks indicate a 476 significant difference at $\mathrm{P}<0.05$ by the generalized linear model with binomial error distribution ad477 justed using Holm-Bonferroni correction. 




Fig 1 


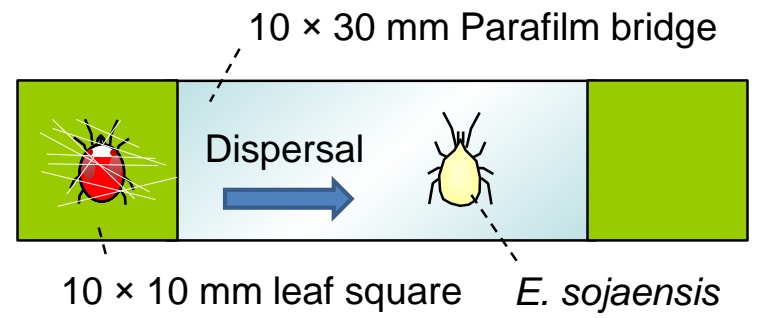

Fig 2 




Fig 3 

(a) Survival rate
(b) Dispersal rate
(c) Remaining rate

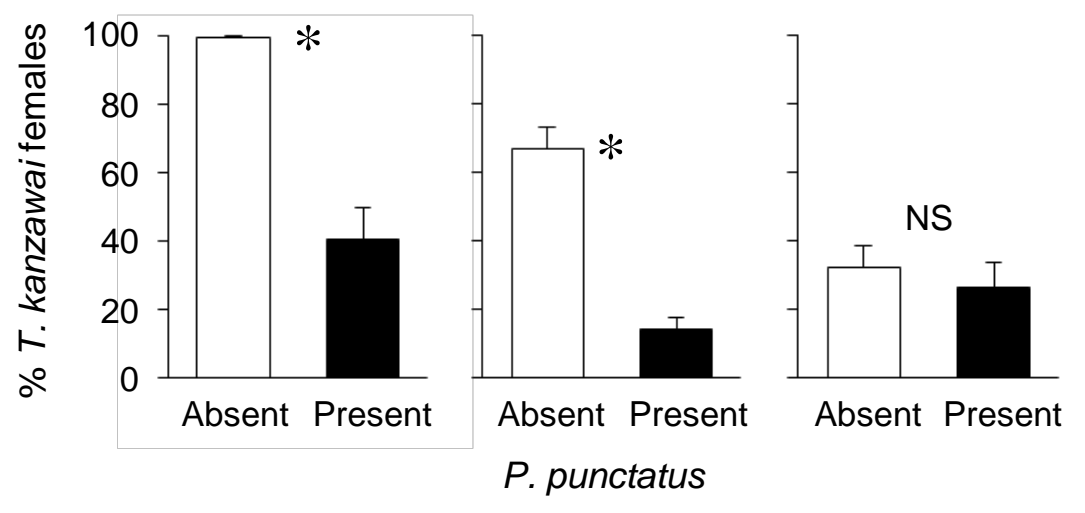

Fig 4 

(a) Survival rate
(b) Dispersal rate
(c) Remaining rate
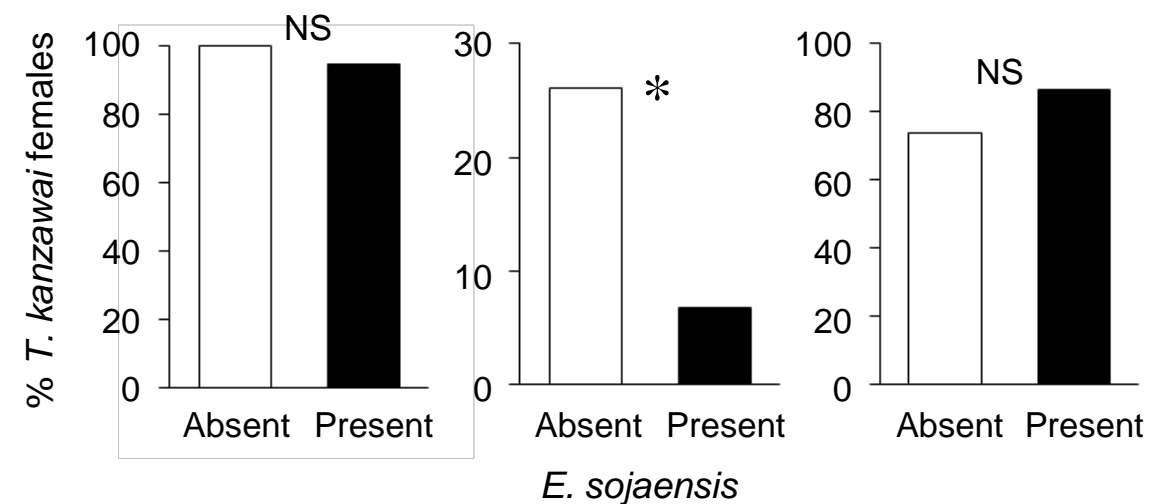

Fig 5 

(a) Survival rate
(b) Dispersal rate
(c) Patch colonization
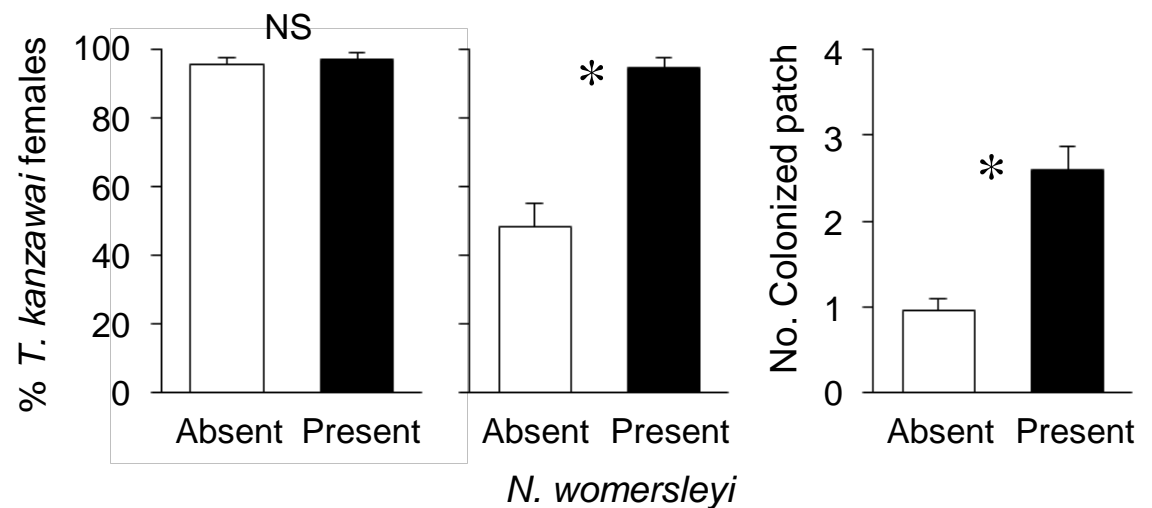

Fig 6 